\title{
ESPAÇO PÚBLICO, ESPAÇOS PÚBLICOS
}

\author{
Paulo Cesar da Costa Gomes \\ Universidade Federal do Rio de Janeiro
}

$\mathrm{Na}$ Geografia, as expressões "espaço público" ou "espaços públicos" aparecem comumente como uma denominação genérica para áreas urbanas abertas. Desde os anos 2000, entretanto, a discussão sobre esses espaços ganha proeminência e, aos poucos, a autonomia temática vêm se consolidando. Por isso, não surpreende a aparição tardia dessa denominação nos dicionários especializados, sua ausência nos manuais da disciplina e seu demorado reconhecimento como um campo para a pesquisa geográfica. Ainda hoje, poucos são os colóquios, comissões ou grupos acadêmicos dedicados ao tema a despeito das inúmeras possibilidades analíticas que oferece. 0 exame da literatura geográfica já nos permite, no entanto, uma análise crítica da massa de trabalhos e a proposição de um elenco de aspectos e problemas comuns trazidos sob a chancela desse tema.

Um primeiro problema nasce do uso da expressão espaço público em diferentes campos de conhecimento. A filosofia política, uma das pioneiras a utilizar essa noção, tem na tese de J. Habermas, nos anos 1960, um marco indiscutível. Aí se privilegia a descrição das atitudes, da mentalidade e de um conjunto de direitos que, em determinado lugar e momento, começam a se impor como molde de interação social. Assim, no século XVIII europeu, mudanças estruturais levaram à constituição de uma esfera pública burguesa, construída em um 'espaço' social situado entre a sociedade civil e o Estado moderno, onde cidadãos podem dialogar e discutir questões de interesse comum. Por isso, esse 'espaço' cumpre uma função política. A atenção da filosofia política se dirige para um domínio abstrato de relações e estruturas sociais e suas transformações. Entretanto, por óbvio, estas mudanças se constituíram também em um espaço físico, material. Uma esfera pública não poderia existir sem que, simultaneamente, um espaço concreto se conformasse, condição necessária para que essas relações abstratas existam e se realizem. Ainda que as transformações físico-espaciais na constituição de uma esfera pública apareçam em Habermas e em outros pensadores da filosofia política, a exemplo de $\mathrm{H}$. Arendt, elas não constituem um objetivo central desses autores, mas sim da Geografia. É falaciosa pois a aparente dicotomia entre "esfera e espaços públicos" como se não fossem solidários na construção e existência do mesmo processo social.

Por outro lado, arquitetos, urbanistas e muitos geógrafos, de modo oposto, utilizam a noção de espaço público como denominação para todo e qualquer espaço urbano livre e aberto. 0 estatuto público não é discutido como produto histórico, como forma de agenciamento social, como configuração de um tipo de vivência. Espaços públicos são associados a certas formas físicas - ruas, praças, parques, etc. Essas formas, no entanto, só ganham sentido na maneira como são estruturadas e vividas, não possuem amalgamado um conteúdo transcendente e absoluto.

Não nos é autorizado concluir a partir da expressão física de uma rua que esta seja um espaço público, independentemente do momento, do lugar em que se encontra e, sobretudo, da maneira pela qual é utilizada. 0 estatuto público possui determinadas características das quais derivam propriedades. Essas características não estão de maneira indissociável presentes nessas formas. Uma rua pode fazer parte de um empreendimento privado. Pode ter uma condição ambígua, como é o caso, por exemplo, de alguns centros comerciais, de parques temáticos, de condomínios fechados etc. cujo estatuto jurídico é privado - espaços privados de uso público. A nuance é importante pois as regras do uso, embora controladas pela potência pública, não emanam apenas dela. Proprietários e administradores criam normas, delimitações e controles com a condição de não ferir os princípios legais estabelecidos para esses logradouros de uso público. 
Um dos fundamentos das ruas é o de serem vias que permitem a circulação, a qualidade pública, entretanto, é uma condição que não se confunde com essa função prática. 0 estatuto público depende de como esse espaço é concebido, usado e vivido. Assim também, ainda que submetida à tutela de administrações públicas, nem sempre o modo de agir e de viver nesses espaços será necessariamente público. Quantas ruas são apropriadas por diferentes grupos, rompendo regras que caracterizam um contrato do tipo público? Não apenas as transgressões explícitas das regras, mas também certos comportamentos podem desvirtuar ou contrariar essa qualidade. Pensemos, por exemplo, nas ruas das pequenas cidades, em seu uso, na maneira com elas são vistas e tratadas como extensões das casas e dos usos de tipo familiar que aí podem predominar, em completa oposição ao uso propriamente público.

Dessas considerações, somos levados a constatar que o aspecto mais importante de um domínio público são os princípios que estruturam as interações entre as pessoas. Eles garantem as bases de uma vida em comum entre indivíduos autônomos e independentes que, em tese, não se conhecem e não dispõem de outros laços. Lembremos que o simples agrupamento de pessoas não basta para caracterizar um público. Esse estatuto é produto de regulações bastante específicas. A estrutura que as mantém unidas e cooperando é formada por um conjunto de disposições que garantem a independência de julgamento e de manifestação das pessoas consideradas nesse conjunto. Por isso, elas compõem um corpo político. São os elementos que formam esse conjunto de disposições e regras que necessitam estar presentes e ativos sobre um espaço para que nele atue um conjunto de pessoas estruturado a partir dessas regulações - em suma, um público.

Esse é o cerne do problema que atravessa a bibliografia sobre o tema, a falta de uma discussão precisa sobre a natureza dos espaços públicos. Daí deriva a dificuldade em conhecer os limites e a extensão da definição. Isso não se resolve pela simples associação com os regimes de propriedade, não se resolve tampouco pela apreciação das condições de acesso, como majoritariamente tem curso no senso comum, basta observar as muitas dependências administrativas públicas que têm acesso restrito.

Há aqueles que querem distinguir espaços públicos e lugares públicos. Ao primeiro corresponderia uma institucionalidade política. Espaços públicos seriam só aqueles onde há uma finalidade dirigida a construir e controlar as regras da vida pública - aparelho burocrático, assembleias, câmaras, comícios etc. A vida pública vernacular e seus espaços cotidianos seriam lugares públicos. Poucos autores atribuem um significado político à simples permanência e uso dos espaços públicos. É possível, no entanto, arguir que a chamada "vida pública urbana", ou seja, os rituais que regulam a co-presença de pessoas com expectativas, interesses e valores muito diversos sob o mesmo espaço, não resulta de uma ação espontânea. Trata-se de um longo processo de conquistas de direitos. De tão generalizados, esses rituais podem parecer naturais, mas não são. Permanecer nos espaços públicos, com todos os direitos que eles asseguram, é um exercício político na vida social. Afirmar a livre expressão da heterogeneidade nestes espaços constitui outro fundamento da vida democrática. Todos os dias, nos espaços públicos se expõem ações que poderiam ser concebidas como manifestações políticas: formas de apresentação, comportamentos, atitudes que tem potencial transformador e de questionamento dos valores e das regras. Ao se manifestar produzem formas de adesão e de conflito, ou seja, produzem um diálogo a respeito da possibilidade de se incorporar ou não essas ações, em outros termos, surge um diálogo político. É neste sentido que a palavra "política" se vincula com suas raízes históricas da Polis.

Outro problema é a recorrente denúncia dos avanços da privatização. São inúmeros os trabalhos nos quais se descrevem casos que indicariam o processo de elipse do caráter público dos espaços, por uma atividade, por uma restrição do uso ou comportamento, por um controle do acesso etc. É frequente a confusão entre dois estatutos espaciais muito diversos: o comum e o público. Partese da ideia que um espaço público permitiria o livre acesso, seria um espaço de todos. Ora, isso corresponde a um espaço do tipo comum. Ocorre com frequência em grupos sociais que têm como pressuposto a existência de uma similar vontade e interesse de todos os seus membros. Trata-se, portanto, de uma comunidade e não de uma sociedade que, ao contrário, pressupõe a relação entre diferentes indivíduos. Membros de uma comunidade e indivíduos que compõem um público são categorias que absolutamente não se confundem em termos de definição, de estatuto e de estrutura social. Se não há um procedimento teórico-metodológico rigoroso, institutos tão diversos, como comunidade e público, podem ser apresentados como correlatos ou similares e a decisão sobre o que considerar como processo de privatização é imprecisa e arbitrária. Os espaços públicos são tratados como se fossem dados gerais e absolutos e qualquer apropriação se confundiria com privatização. Escapa desse raciocínio o fato de que as categorias público e privado compõem um par e só há análise consistente quando percebidas em um universo não dicotômico. Desde o pioneiro estudo de Habermas essa 
demonstração foi feita e segue sendo um elemento que discrimina as sólidas análises daquelas que confundem privatização com qualquer forma de apropriação.

Finalmente, um último aspecto problemático dominante na literatura sobre os espaços públicos é o profético anúncio sobre seu próximo e inexorável fenecimento. Nesses diagnósticos são sempre enfatizados seu incorreto funcionamento, suas distorções, as disputas que aparecem, tudo isso compondo os sintomas de seu esperado fim. Os seguidores dessa interpretação são numerosos e há mesmo um grupo de autores anglo-saxões comprometidos com a chamada "tese do fim dos espaços públicos".

Na maior parte desses textos o tratamento consiste em demonstrar quão desigual, injusto, censurável, em suma "imperfeito", é o funcionamento desses espaços. Argui-se como evidencia a distância entre os valores proclamados idealmente (isonomia, isocracia e isegoria) e aquilo que se observa nos diversos casos empíricos estudados. Algo que não deveria escapar a esses críticos é que, ao contrário das doutrinas escatológicas, o funcionamento dos espaços públicos nunca foi pensado como um modelo ideal, de perfeição e obliteração de conflitos. Espaços públicos não são produtos dados e acabados, uma instituição que, uma vez estabelecida, traria a paz da consensualidade e a perfeita igualdade nas sociedades democráticas. Espaços públicos são os lugares em que os problemas aparecem e se transformam em debates, em diálogo e em possibilidade de ajuste e compromissos. Por isso, não anulam os conflitos, ao contrário, são canais de comunicação e de visibilidade de oposições. Não existe um modelo definitivo a partir do qual só virtudes e harmonia seriam gestadas. A dificuldade desses autores é trabalhar fora da referência fantasiosa dos modelos utópicos. Os sintomas de uma destruição por eles apontados podem ser lidos como publicização dos problemas que esses espaços colocam em jogo ou fazem aparecer. A única verdadeira ameaça a eles consiste nas ações que comprometem a publicidade, ou seja, as regras que os estabelecem, a capacidade de gerar exposição e condições comunicacionais.

É fácil perceber que esses problemas e aspectos aqui elencados não são mutuamente excludentes. Aparecem com frequência em associação e compõem um quadro, salvo poucas exceções, bastante homogêneo da produção bibliográfica em Geografia sobre o tema dos espaços públicos. Uma vez cumprido esse percurso, podemos nos dedicar então a tentar extrair alguns pontos essenciais que são sinteticamente expostos a seguir.
Componentes e propriedades essenciais dos espaços públicos

A rigorosa definição daquilo que está sendo assentado como atividade pública é o que nos capacita a estabelecer as qualidades e propriedades desses espaços e nos autoriza a refletir sobre sua pertinência e importância. Evidentemente, o rigor da definição não deve se portar como um obstáculo para a observação da singularidade pela qual se constroem as manifestações fenomênicas. Esse é um grande problema metodológico que atravessa a história das ciências sociais. A solução consiste em não sobrevalorizar o geral em detrimento da particularidade dos aspectos, mas tampouco submergir ao peso da singularidade absoluta dos eventos. Urge examinar os padrões de variabilidade daquilo que está sendo identificado, sua localização no tempo e no espaço, sua transformação, ou seja, tudo aquilo que faz mudar a forma. Para isso, precisamos adjurar a sedução de trabalhar com categorias que pouco se aplicam às efetivas experiências empíricas às quais, em princípio, deveriam corresponder.

O público se constitui de uma reunião de entes, indivíduos, com qualidades, interesses, valores e projetos diversos. A convivência impõe regulações e limites para a satisfação parcial desses diferentes interesses. A pessoa pública, o cidadão é um sujeito de direito e de deveres. Tudo isso, é fácil perceber, variou e varia em termos de tempo e espaço.

A reunião é também física, se passa sobre um espaço, objeto ele também de regulações e limites, exprimindo na sua organização material os pactos e convenções. É a existência e a forma de viver nesses espaços que permite uma convivência pública e democrática. Por isso, ao contrário daquilo que intuitivamente se apresenta como definição, os espaços públicos são fortemente normatizados e discriminam, usos, comportamentos, funções, acessos etc. Os princípios da vida em comum em sociedades republicanas organizam materialmente esses espaços. Pistas de rolamento, calçadas, meiofio, faixas de pedestres, semáforos, entre outros elementos, são, nas ruas, expressões claras desses acordos e compromissos que regulam comportamentos, fluxos, funções, condições de acessos em diferentes circunstancias e são derivados de direitos e deveres socialmente e republicanamente estabelecidos. Esse tipo de normatização constitui, pois, a qualidade primeira desse espaço e um dos seus componentes essenciais.

O segundo elemento central de um espaço público é a heterogeneidade elementar que está subsumida na reunião de indivíduos. Espaços públicos colocam ao abrigo à manifestação da individualidade e, portanto, 
oferecem condições para o reconhecimento das diferenças e encorajam ações afırmativas. Do ponto de vista político, espaços públicos respondem à questão de saber como estabelecer um terreno de vida comum sem que para essa convivência precisemos renunciar às nossas diversidades em termos de opinião, vontades, valores, atitudes e formas de apresentação. Tratase, portanto, de uma co-presença espacial sem que isso pretenda reduzir ou aplanar as características individuais. Não há por isso a promessa de que essa convivência seja sempre harmônica e sem conflitos, ao contrário, o resguardo da diversidade é a possibilidade de reconhecermos direitos em outras formas de pensar e de agir que, embora contrariem as nossas, encontram também legitimidade em se manifestar e existir socialmente. Aprenderemos a conviver com elas, não sem reação, mas encontrando formas e delimitações que compatibilizem a vida de diferentes indivíduos, dividindo um mesmo espaço. Quanto maior for a heterogeneidade de interesses, de valores, das formas de pensar e agir que um espaço é capaz de abrigar, maior é o seu grau de publicidade, ou seja, sua capacidade de operar a convivência entre indivíduos diferentes que dividem um espaço de vida.

O terceiro componente essencial dos espaços públicos diz respeito ao seu poder comunicacional. Uma vez que nos é garantida a legitimidade das diferenças individuais, estar junto sobre um mesmo espaço significa a possibilidade de exibir características próprias e independentes. Tornar público significa oferecer ao julgamento e à opinião dos outros indivíduos essas características. Trata-se de um exercício veiculado a partir de uma infinidade de repertórios, verbais, gestuais, comportamentais, do vestuário, das formas de apresentação enfim, de tudo aquilo que produz significação social. A comunicação é ativada por compartimos um mesmo espaço. Ainda que as ações demonstrem pouca atenção ou indisponibilidade de entrar em contato, ao se passar sobre um espaço público, se transformam imediatamente em comunicação. Essa qualidade é alias aquela que corresponde à origem e ao uso da palavra publicidade até o século XIX: tornar público, exibir, mostrar.

Desses componentes essenciais derivam propriedades. Quando elas estão ausentes, há fortes chances de que esses espaços não estejam funcionando como públicos. Uma primeira propriedade é o desenvolvimento de uma cultura publica, isto é, formas codificadas de interação interpessoal entre desconhecidos. Trata-se de um código comportamental, dotado de certa plasticidade, utilizado como elemento de ligação entre pessoas que não têm familiaridade. Esse protocolo prevê atitudes, distancias, gestos, condições e formas de interação. A organização espacial é uma de suas mais importantes grades deinformação, delimitação, leitura e interpretação. Os tipos de espaços classificam ações, funções, perímetros etc. Tudo está fortemente normatizado, seja a partir de explícitas disposições escritas, seja, por consuetudinários contratos. A vida social nos espaços públicos depende do conhecimento e manuseio desse código. 0 espaço público é um elemento comunicacional primário, não apenas na maneira como é organizado, mas também pelo modo como é ativado nas ações que aí tem lugar. São espaços de amplo diálogo social e evidentemente não o estamos restringindo à expressão oral, atos, gestos, formas de apresentação e até mesmo a simples presença é portadora de sentido e de comunicação. Por isso, espaços públicos convidam à observação e a vivência da alteridade. Por último, como espaços de comunicação, de visibilidade, além de permitirem a observação são portadores de reflexividade: observamos e somos observados. A simultaneidade das ações transforma atos, comportamentos e formas de apresentação em informação, em interpelação e em diálogo.

A despeito das imensas possibilidades para a pesquisa em Geografia, os espaços públicos ainda são pouco estudados e, muitas vezes, quando aparecem estão submetidos a concepções com premissas interpretativas estabelecidas a priori. Os resultados são, assim, gerais e banais. Por isso, dinâmicas que cotidianamente se apresentam nesses espaços continuam a constituir desafios para uma interpretação geográfica. Quando dizemos geográfica é porque essa análise deve estar comprometida com o campo de investigação que coloca no centro as questões relativas ao jogo de posições, à trama espacial das dinâmicas sociais. Assim, uma análise geográfica dos espaços públicos tem necessidade de compreender as ações e comportamentos aí presentes como associados à morfologia, à forma concreta de organização do espaço. É a partir dessa conexão que podemos produzir interpretações geográficas dos seus significados. 
ARENDT, H. O que é política? Rio de Janeiro: Bertrand Brasil, 1998.

BORJA, J.; MUXI, Z. El espacio público: ciudad y ciudadania. Barcelona: Electa, 2003.

GOHEEN, Peter. "Public space and the geography of the modern city." Progress in Human Geography Vol. 22, No 4, pp. 479-496, 1998.

GOMES, P.C.C. A condição urbana: ensaios de geopolítica da cidade. Rio de Janeiro, Bertrand Brasil, 2002.

GOMES, P. C. C. "Espaços públicos: um modo de ser do espaço, um modo de ser no espaço. " In: CASTRO, I; GOMES, P. \& CORRÊA, R. Olhares Geográficos: modos de ver e viver o espaço. Rio de Janeiro: Bertrand Brasil, pp. 19-41. 2012. HABERMAS, Jürgen. Mudança estrutural da esfera pública. Rio de Janeiro: Editora Tempo Brasileiro, 1984.

HOWELL, P. "Public space and the public sphere: political theory and the historical geography of modernity." Environment and Planning: Society and Space, volume 11, pp. 303-322, 1993.

LOW, S.; SMITH, N. (Eds.). The politics of public space. London and New York: Routledge, 2006.

SANTOS, M. O espaço do cidadão. São Paulo: Nobel, 1987.

SERPA, A. O espaço público na cidade contemporânea. São Paulo: Contexto, 2007.

SMITH, J.; LIGTH, A. The Production of Public Space. Maryland: Rowan \& Littlefield, 1998. 